\title{
Adsorption of 1,2-dichlorobenzene from water to carbon nanotubes
}

\author{
Xianjia Peng ${ }^{\mathrm{a}, *}$, Yanhui Li ${ }^{\mathrm{b}}$, Zhaokun Luan ${ }^{\mathrm{a}, 1}$, Zechao Di ${ }^{\mathrm{b}}$, \\ Hongyu Wang ${ }^{c}$, Binghui Tian ${ }^{\mathrm{a}}$, Zhiping Jia ${ }^{\mathrm{a}}$ \\ a State Key Laboratory of Environmental Aquatic Chemistry, Research Center for Eco-Environmental Sciences, \\ Chinese Academy of Sciences, Beijing 100085, China \\ $\mathrm{b}$ Department of Mechanical Engineering, State Key Laboratory of Automotive Safety and Energy, \\ Tsinghua University, Beijing 100084, China \\ ${ }^{\mathrm{c}}$ Institute of environmental science, Zhejiang University, Hangzhou 310029, Zhejiang, China
}

Received 3 April 2003; in final form 28 May 2003

Published online: 1 July 2003

\begin{abstract}
The as-grown CNTs and graphitized CNTs were used as adsorbents to remove 1,2-dichlorobenzene from water. The experiments demonstrate that it takes only $40 \mathrm{~min}$ for CNTs to attain equilibrium and the adsorption capacity of asgrown and graphitized CNTs is 30.8 and $28.7 \mathrm{mg} / \mathrm{g}$, respectively, from a $20 \mathrm{mg} / \mathrm{l}$ solution. CNTs can be used as adsorbents in a wide $\mathrm{pH}$ range of 3-10. Thermodynamic calculations indicate that the adsorption reaction is spontaneous with a high affinity and the adsorption is an endothermic reaction.
\end{abstract}

(c) 2003 Elsevier Science B.V. All rights reserved.

\section{Introduction}

Since Iijima's observations in 1991 [1], carbon nanotubes (CNTs) have been the subject of an increasing number of experimental and theoretical studies [2]. CNTs can be thought of as cylindrical hollow micro-crystals of graphite [3]. Because they have large specific area, CNTs have attracted researchers' interest as a new type of adsorbent. Long and Yang [4] first reported in 2001 that

\footnotetext{
${ }^{*}$ Corresponding author. Fax: +861062849198 .

E-mail address: pencil77@163.net (X.Peng), luanzk@mail. rcees.ac.cn (Z. Luan).

${ }^{1}$ Also corresponding author.
}

CNTs can be more efficient for the removal of dioxins than activated carbon. Li et al. [5] found that acid-refluxed CNTs can be good $\mathrm{Pb}^{2+}$ adsorbents and have great potential applications in environmental protection. They also prepared amorphous $\mathrm{Al}_{2} \mathrm{O}_{3}$ supported on carbon nanotubes $\left(\mathrm{Al}_{2} \mathrm{O}_{3} / \mathrm{CNTs}\right)$ and found that it has a much higher adsorption capacity of fluoride than $\gamma-\mathrm{Al}_{2} \mathrm{O}_{3}$ and predicted that it is very suitable for potential applications in fluoride removal from water [6]. But until now little study is done on adsorption of organic pollutants to CNTs.

Chlorobenzenes (monochlorobenze, dichlorobenzene, and trichlorobenzenes) are used as solvent, heat transfer agents, insect repellent, 
deodorants, degreasers and intermediates in dye and pesticide synthesis. Consequently, they are detected in surface water and ground-water and in some biological tissues and they are identified as priority pollutants by US Environmental Protection Agency [7,8]. Among chlorobenzenes, 1,2-dichlorobenzene (DCB) is a manufactured organohalogen compound and is used as a solvent for degreasing hides and wool. It also serves as a synthetic reagent for dye manufacture [9]. It is chemically stable and their photochemical degradation in soil and aquatic environments is limited [7]. Widespread uses over several decades have resulted in contamination of environment and human exposure to DCB. In order to reduce DCB discharge into aquatic environment, effective measures should be taken to remove DCB from wastewater.

DCB is little dissolvable and often at low concentrations in water. The removal of toxic compounds represents a problem, particularly when they are at low concentrations. The method employed are either destructive oxidation by means of ozone, hydrogen peroxide, manganese oxides or adsorption by porous solids such as activated carbon, fly ash and natural or pillared clays [10]. Among these methods, adsorption is regarded as a promising method for the removal of micropollutants. By a adsorption-desorption process, contaminants in water can be recycled. So, it is of great importance to develop this kind of method and new types of efficient adsorbents. In this research, in order to show the potential applications of CNTs in the treatment of waste water which contains organic pollutants, two kinds of CNTs, the as-grown CNTs and graphitized CNTs were used to remove DCB from water.

\section{Experimental}

\subsection{Materials}

The as-grown CNTs were prepared by catalytic pyrolysis of the propylene-hydrogen $\left(\mathrm{C}_{3} \mathrm{H}_{6}\right.$ : $\mathrm{H}_{2}=2: 1$ ) mixture at $750{ }^{\circ} \mathrm{C}$ in a ceramic tube furnace using $\mathrm{Ni}$ particles as catalysts. The graphitized CNTs were prepared by treating the as-grown CNTs in nitrogen atmosphere at $2200{ }^{\circ} \mathrm{C}$ for $2 \mathrm{~h}$. The specific area of as-grown and graphitized CNTs is 134.0 and $126.0 \mathrm{~m}^{2} / \mathrm{g}$, respectively. DCB of $99 \%$ purity was obtained from Beijing Chemical Reagent Company.

\subsection{Methods}

DCB solution was prepared by dissolving DCB in deionized water by sonication. Batch adsorption experiments were performed in glass bottles. To each bottle, $100 \mathrm{ml}$ DCB solution of prescribed concentration and $0.05 \mathrm{~g}$ CNTs were added. The $\mathrm{pH}$ was adjusted using $1 \mathrm{M} \mathrm{HCl}$ or $1 \mathrm{M} \mathrm{NaOH}$. The bottles were capped with glass screws and then were mounted on a HZQ-C shaker and shaken. After equilibrium the solution was centrifuged and the supernatant solution was analyzed spectrophotometrically using a Hitachi model U-3010 doubling beam UV/vis spectrophotometer. Matched $10 \mathrm{~mm}$ quartz cells were used. DCB adsorbed by CNTs was calculated as follows:

$q=\left(C_{0}-C_{\mathrm{t}}\right) V / m$,

where, $q$-DCB adsorbed $(\mathrm{mg} / \mathrm{g}) ; C_{0}$, initial concentration of DCB $(\mathrm{mg} / \mathrm{l}) ; C_{\mathrm{t}}$, concentration of DCB after shaken for a certain period of time $(\mathrm{mg} /$ 1); $V$, solution volume $(L) ; m$, CNTs dosage (g).

\section{Results and discussion}

Fig. 1 shows the effect of contact time on the adsorption of DCB to CNTs. The removal in-

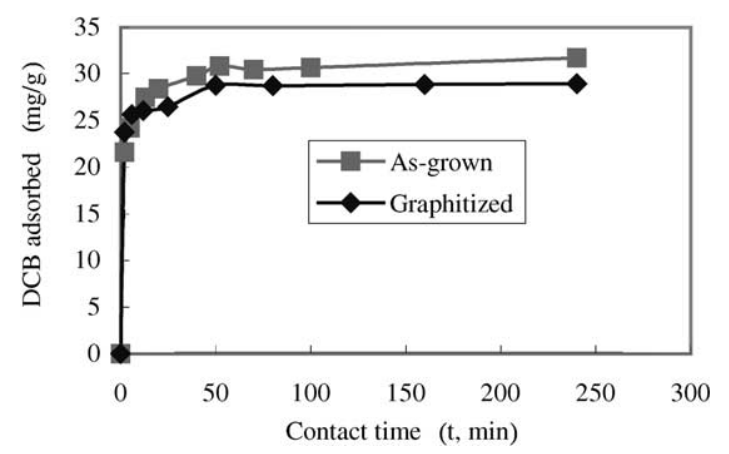

Fig. 1. The effect of contact time on the adsorption of DCB to CNTs (pH $\left.5.5 T=25{ }^{\circ} \mathrm{C} C_{0}=20 \mathrm{mg} / \mathrm{l}\right)$. 
creases with time in the first $40 \mathrm{~min}$ and adsorption reaches equilibrium at $40 \mathrm{~min}$ for both as-grown CNTs and graphitized CNTs. DCB adsorbed by as-grown and graphitized CNTs reaches 30.8 and $28.7 \mathrm{mg} / \mathrm{g}$, respectively. Generally, it takes a long residence time for activated carbon, the most commonly used adsorbent, to attain equilibrium (e.g., it takes $20 \mathrm{~h}$ for adsorption of phenol [11]). In contrast, less time is taken for CNTs. Perhaps it is because CNTs have no porous structure like traditional adsorbents (e.g., activated carbon) in which cases adsorbate has to move from the exterior surface to the inner surface of the pores on adsorbents to achieve equilibrium. The short time needed to achieve equilibrium also suggests that CNTs have very high adsorption efficiency and have a potential in removal of DCB from water.

Fig. 2 shows the effect of $\mathrm{pH}$ on the adsorption. It is evident that the removal of DCB by both asgrown CNTs and graphitized CNTs fluctuates very little in the $\mathrm{pH}$ range $3-10$. The removal rate remaining almost constant in such a wide $\mathrm{pH}$ range suggests that CNTs are excellent adsorbents for DCB removal. When $\mathrm{pH}$ exceeds 10 , the removal drops suddenly. It has already been known that there are some oxygen groups such as carboxylic groups $(-\mathrm{COOH})$ and hydroxylic groups $(-\mathrm{OH})$ on the surface of CNTs. According to Dubinin [12], the water molecules adsorbed to the oxygen groups on carbon surface become secondary adsorption centers, which retain other water molecules by means of hydrogen bonds. As a result, complexes of associated water form. At higher $\mathrm{pH}$ values,

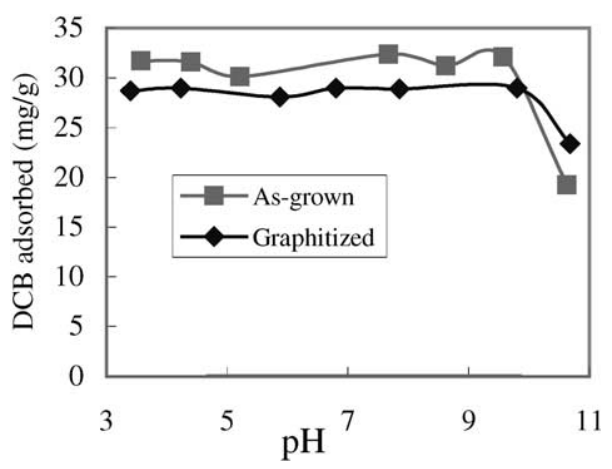

Fig. 2. The effect of $\mathrm{pH}$ on the adsorption of DCB to CNTs $\left(T=25{ }^{\circ} \mathrm{C} C_{0}=20 \mathrm{mg} / \mathrm{l} t=24 \mathrm{~h}\right)$. these oxygen groups can easily be ionized. Puri and Mahajan [13] have reported that the replacement of $\mathrm{H}^{+}$by $\mathrm{Na}^{+}, \mathrm{K}^{+}$and $1 / 2 \mathrm{Ca}^{2+}$ on charcoal causes charcoal to adsorb more water due to the fact that the ionization of charcoal associated with metal cations was greater than that of the H-charcoal. It can also be suggested that because more oxygen groups on the surface of CNTs ionize, more water is adsorbed by these groups at higher $\mathrm{pH}$ values. Thus, when water cluster forms on these oxygen groups, the adsorption is affected in two ways. First, since these oxygen groups are located on the surface of CNTs, the formation of water cluster hinders access to the surface. A second possible influence of water adsorption is interference with surface carbonyl groups. These groups can adsorb organics through donor-accepter complex formation. The formation of water cluster on carbonyl groups is suspected to block adsorption on the carbonyl sites [14]. If water cluster is indeed the cause of the decreased capacity observed at higher $\mathrm{pH}$, it is to expected that the effect would be reduced if the number of oxygen groups on the surface of CNTs were reduced. This is confirmed by the observed phenomenon that adsorption capacity of graphitized CNTs decreased much less when $\mathrm{pH}$ exceeds 10 . Because after being treated at high temperature, the number of oxygen groups on the surface of graphitized CNTs is reduced.

Figs. 3 and 4 show adsorption isotherms of asgrown and graphitized CNTs. The Freundlich model was employed for adsorption for both as-grown and graphitized CNTs. Freundlich

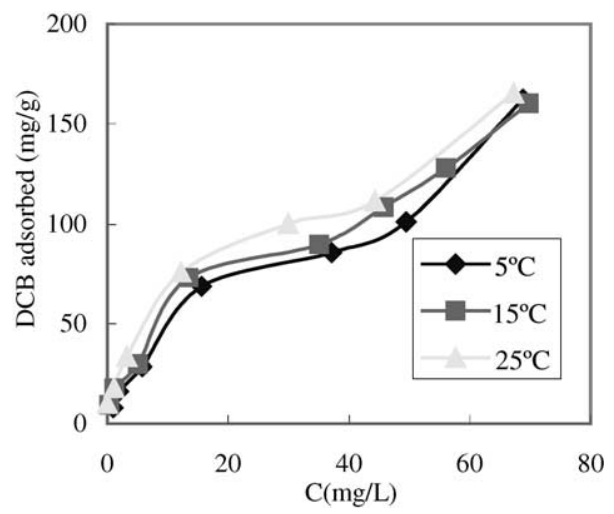

Fig. 3. Isotherms of As-grown CNTs ( $t=24 \mathrm{~h} \mathrm{pH} \mathrm{5.5).}$ 


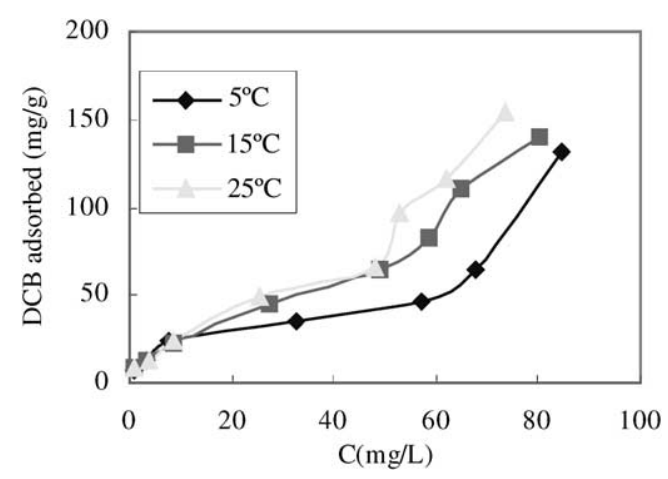

Fig. 4. Isotherms of graphitized CNTs $(t=24 \mathrm{~h} \mathrm{pH} 5.5)$.

adsorption isotherm represents the relationship between the amount of DCB adsorbed by per unit mass of adsorbent $\left(q_{\mathrm{e}}\right)$ and the concentration of DCB at equilibrium $\left(C_{\mathrm{e}}\right)$ [15]:

$q_{\mathrm{e}}=K C_{\mathrm{e}}^{\frac{1}{n}}$

or : $\log q_{\mathrm{e}}=\log K+\frac{1}{n} \log C_{\mathrm{e}}$,

where $K$ and $n$ are constants representing the adsorption capacity and intensity of the adsorption, respectively. Constants of Freundlich adsorption isotherm models for adsorption of DCB to CNTs are listed in Table 1. As can be seen from Table 1, the data fit Freundlich adsorption isotherm well. Fig. 3 and Fig. 4 also show that the adsorption of DCB to both as-grown CNTs and graphitized CNTs increases with the increase in temperature. This indicates that adsorption of DCB to CNTs is an endothermic reaction. Thermodynamic parameters were calculated from the variation of the thermodynamic equilibrium constant $K_{0}$ with the change in temperature. The calculation methods employed are discussed in detail by Niwas. et al [16]. $K_{0}$ for the adsorption reaction can be defined as follows:
$K_{0}=\frac{a_{\mathrm{s}}}{a_{\mathrm{e}}}=\frac{v_{\mathrm{s}}}{v_{\mathrm{e}}} \frac{C_{\mathrm{s}}}{C_{\mathrm{e}}}$,

where $a_{\mathrm{s}}$ is the activity of adsorbed solute, $a_{\mathrm{e}}$ is the activity of the solute in solution at equilibrium, $C_{\mathrm{s}}$ is the surface concentration of DCB in millimoles per gram of CNTs, $C_{\mathrm{e}}$ is the concentration of DCB at equilibrium $(\mathrm{mmol} / \mathrm{ml}), v_{\mathrm{s}}$ is the activity coefficient of the adsorbed solute and $v_{\mathrm{e}}$ is the activity coefficient of the solute in solution. As the concentration of the solute in the solution approaches zero, the activity coefficient approaches unity, reducing Eq. (4) to the following form:

$K_{0}=\frac{a_{\mathrm{s}}}{a_{\mathrm{e}}}=\frac{C_{\mathrm{s}}}{C_{\mathrm{e}}}$.

Values of $K_{0}$ are obtained by plotting $\ln \left(C_{\mathrm{s}} / C_{\mathrm{e}}\right)$ versus $C_{\mathrm{s}}$ and extrapolating $C_{\mathrm{s}}$ to zero. The straight line obtained is fitted to the points based on a least-squares analysis. Its intercept with the vertical axis gives the values of $K_{0}$. Standard free energy changes $\left(\Delta G_{0}\right)$ for interactions are calculated from the relationship:

$\Delta G^{0}=-R T \ln K_{0}$,

where $R$ is the universal gas constant and $T$ is the temperature in Kelvin. The average standard enthalpy change $\left(\Delta H^{0}\right)$ is then calculated from the Van't Hoff equation:

$\ln K_{0}\left(T_{3}\right)-\ln K_{0}\left(T_{1}\right)=\frac{-\Delta H^{0}\left(T_{1} \text { to } T_{3}\right)}{R}\left(\frac{1}{T_{3}}-\frac{1}{T_{1}}\right)$,

where $T_{3}$ and $T_{1}$ are two different temperatures. Standard entropy changes $\left(\Delta S^{0}\right)$ are calculated using the equation

$\Delta G^{0}=\Delta H^{0}-T \Delta S^{0}$.

The values obtained are given in Table 2. A positive value of the standard enthalpy change

Table 1

Constants of Freundlich adsorption isotherm models for adsorption of DCB to CNTs

\begin{tabular}{|c|c|c|c|c|c|c|}
\hline \multirow[t]{2}{*}{$T\left({ }^{\circ} \mathrm{C}\right)$} & \multicolumn{3}{|c|}{ As-grown CNTs } & \multicolumn{3}{|c|}{ Graphitized CNTs } \\
\hline & $1 / n$ & $\log K$ & $R^{2}$ & $1 / n$ & $\log K$ & $R^{2}$ \\
\hline 5 & 0.6516 & 0.9671 & 0.9819 & 0.5536 & 0.8254 & 0.9737 \\
\hline 15 & 0.5172 & 1.2005 & 0.9859 & 0.6576 & 0.7972 & 0.9769 \\
\hline 25 & 0.5164 & 1.2524 & 0.9868 & 0.6788 & 0.7983 & 0.9572 \\
\hline
\end{tabular}


Table 2

Values of various thermodynamic parameters for the adsorption of DCB to CNTs

\begin{tabular}{|c|c|c|c|c|c|c|}
\hline \multirow[t]{2}{*}{$T\left({ }^{\circ} \mathrm{C}\right)$} & \multicolumn{3}{|c|}{ As-grown CNTs } & \multicolumn{3}{|c|}{ Graphitized CNTs } \\
\hline & $\begin{array}{l}\Delta G^{0} \\
\left(\mathrm{~kJ} \mathrm{~mol}{ }^{-1}\right)\end{array}$ & $\begin{array}{l}\Delta H^{0} \\
\left(\mathrm{~kJ} \mathrm{~mol}^{-1}\right)\end{array}$ & $\begin{array}{l}\Delta S^{0} \\
\left(\mathrm{~kJ} \mathrm{~mol}^{-1} \mathrm{~K}^{-1}\right)\end{array}$ & $\begin{array}{l}\Delta G^{0} \\
\left(\mathrm{~kJ} \mathrm{~mol}{ }^{-1}\right)\end{array}$ & $\begin{array}{l}\Delta H^{0} \\
\left(\mathrm{~kJ} \mathrm{~mol}^{-1}\right)\end{array}$ & $\begin{array}{l}\Delta S^{0} \\
\left(\mathrm{~kJ} \mathrm{~mol}^{-1} \mathrm{~K}^{-1}\right)\end{array}$ \\
\hline 5 & -20.36 & 16.40 & 0.132 & -19.04 & 5.95 & 0.090 \\
\hline 15 & -21.79 & 16.40 & 0.133 & -19.73 & 5.95 & 0.089 \\
\hline 25 & -23.00 & 16.40 & 0.132 & -20.84 & 5.95 & 0.090 \\
\hline
\end{tabular}

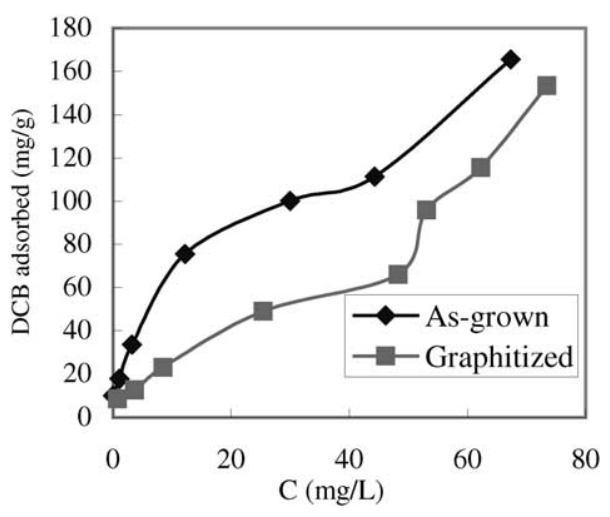

Fig. 5. Isotherms of As-grown and graphitized CNTs at $25^{\circ} \mathrm{C}$ (pH $5.5 t=24 \mathrm{~h}$ ).

indicates that the DCB-CNTs interaction is endothermic. It is supported by the increasing adsorption of DCB with the increase in temperature. Since the free energy changes are negative and are accompanied by positive entropy changes, the reactions are spontaneous with a high affinity for DCB [16].

Adsorption isotherms of as-grown and graphitized CNTs at $25^{\circ} \mathrm{C}$ are plotted in Fig. 5. It is clear that as-grown CNTs are better for adsorption of DCB. Maybe it is because as-grown CNTs have rough surface which made adsorption of organics much easier. However, the heat treatment eliminates defects and the surface of graphitized CNTs becomes smooth after being treated at high temperature. Thus, adsorption of organics decreases.

\section{Conclusions}

CNTs are good adsorbents for the removal of DCB from wastewater. The time needed for adsorption of DCB to CNTs is only $40 \mathrm{~min}$. CNTs can be used as adsorbents in a wide $\mathrm{pH}$ range of 310. When $\mathrm{pH}$ exceeds 10 , because of the ionization of the oxygen groups on the surface and the formation of water cluster on these groups, the adsorption decreases. The negative free energy changes accompanied by a positive entropy changes indicate that the adsorption reactions are spontaneous with a high affinity and adsorption of DCB on CNTs is an endothermic reaction. Asgrown CNTs are better for adsorption of DCB than graphitized CNTs.

\section{References}

[1] S. Iijima, Nature 354 (1991) 56.

[2] V. Meunier, P. Lambin, Carbon 38 (2000) 1729.

[3] T.W. Ebbesen, J. Phys. Chem. Solids 57 (1996) 951.

[4] R.Q. Long, R. Yang, J. Am. Chem. Soc. 123 (2001) 2058.

[5] Y.H. Li, S. Wang, J. Wei, et al., Chem. Phys. Lett. 357 (2002) 263.

[6] Y.H. Li, S. Wang, A. Cao, et al., Chem. Phys. Lett. 350 (2001) 412.

[7] F. Roberge, M.J. Gravel, L. Deschênes, C. Guy, R. Samson, Wat. Sci. Technol. 44 (2001) 287.

[8] G.A. Hill, M.E. Tomusiak, B. Quail, K.M.V. Cleave, Environ. Progr. 10 (1991) 147.

[9] H.F. Lin, R. Ravikrishna, K.T. Valsaraj, Sep. Pur. Technol. 28 (2002) 87.

[10] C. Solisio, A. Lodi, M.D. Borghi, Waste Manage. 21 (2001) 33.

[11] A.A.M. Daifullah, B.S. Girgis, Wat. Res. 32 (1998) 1169.

[12] M.M. Dubinin, in: P.L. Walker Jr. (Ed.), Chemistry and Physics of Carbon, Marcel Dekker, New York, 1966.

[13] B.R. Puri, O.P. Mahajan, Soil Sci. 94 (1962) 162.

[14] H.A. Arafat, M. Franz, N.G. Pinto, Langmuir 15 (1999) 5997.

[15] S. Rengaraj, S.H. Moon, R. Sivabalan, et al., Waste Manage. 22 (2002) 543.

[16] R. Niwas, U. Gupta, A.A. Khan, et al., Colloids Surfaces A: Physicochem. Eng. Aspects 164 (2000) 115. 